\title{
The penetration effects on TanDEM-X elevation using the GNSS and laser altimetry measurements in Antarctica
}

\author{
Jie Zhao ${ }^{\mathrm{a}, \mathrm{c},}, *$, Dana Floricioiu ${ }^{\mathrm{b}}$

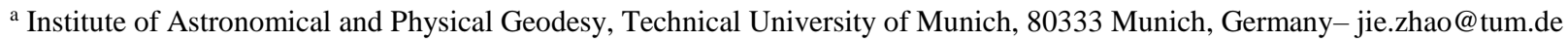 \\ ${ }^{\mathrm{b}}$ Remote Sensing Technology Institute (IMF), German Aerospace Center (DLR), Oberpfaffenhofen, 82234 Weßling, Germany - \\ dana.floricioiu@dlr.de \\ ${ }^{c}$ School of Remote Sensing and Information Engineering, Wuhan University, 430079, Wuhan, China
}

KEY WORDS: TanDEM-X DEM, Penetration Depth, Backscattering coefficient, Blue ice, Dry snow, Antarctica

\begin{abstract}
:
Synthetic Aperture Radar (SAR) has been widely used in many different fields, such as geoscience, climate monitoring, securityrelated applications. However, over natural terrain the radar signal has the ability to penetrate the ground surface which can cause the bias in the elevation measurements. The aim of the paper is to assess the SAR signal penetration effect on the TanDEM-X absolute elevation over ice and snow covered areas and it presents the results concerning the X-band SAR signal penetration effect on dry snow areas and blue ice region. Additionally, the relationship between SAR signal penetration depth and backscattering coefficient is exploited and discussed. In this paper, two study sites, Schirmacher area and Recovery Ice Stream are selected and it is found that the general X-band SAR signal penetration depth is around 3-7 meter on dry snow area while no penetration depth is expected on the blue-ice region.
\end{abstract}

\section{INTRODUCTION}

Glaciers are closely related to the Earth's climate system as the major contributors to the sea level rise and temperate and tropical glaciers also play a significant role in the life of human beings. However, almost $99 \%$ glacial ice on Earth is located in the Polar Regions (Vaughan et al., 2013) and is difficult to investigate through field research. Therefore, it is important to monitor glaciated regions and more over generating accurate up to date Digital Elevation Model (DEM) of these areas will contribute significantly to this application.

Only few available DEMs covered the whole Antarctica are available and they are generated from single data source or multiple data sources with different methods such as an altimetry based DEM developed by (Bamber et al., 2009) and the Radarsat Antarctica Mapping Project (RAMP) DEM of (Liu et al., 1999). These two DEMs generated with decades-old data are widely used, which cannot provide high accuracy Antarctica surface elevation measurements and the surface topographic data (Liu et al., 1999). The TanDEM-X satellite mission provides a good opportunity to do the research of glaciers on a large scale even in remote areas like ice sheets, ice caps and ice fields by providing a global view of the DEM of glaciers with high accuracy, $2 \mathrm{~m}$ vertical accuracy and $6 \mathrm{~m}$ horizontal accuracy.

Over natural terrain such as snow and glacier the radar signal has the ability to penetrate the ground surface and the SAR phase center is located below the natural terrain, consequently, the surface elevation of DEM derived by the Interferometric Synthetic Aperture Radar (InSAR) has a negative bias and lower than the actual surface elevation (Dall, 2007). The bias between the DEM elevation and the terrain elevation can be regarded as the two-way penetration depth $\delta_{\phi}$ of the SAR signal (Dall, 2007). In order to have the high accurate DEM which represents the actual terrain, it is important to investigate the SAR signal penetration effect. In particular, for ice and snow covered areas the SAR signal penetration plays a significant role which will be described in detail in this paper.

\section{METHODOLOGY}

In this section, the basic backscatter theory and the definition of the penetration depth are described in detail. Then, the processing chain of the experiment is presented.

\subsection{Backscattering coefficient}

The backscatter is the reflected wave or signal which changes its forward direction by $180^{\circ}$ while the definition of the backscattering coefficient is the differential scattering cross section per unit volume for a scattering angle of $180^{\circ}$ (Chen et al., 1993). Generally, the radar backscatter of an area on the ground can be represented by a SAR image. The darker area of a SAR image has lower backscatter while the brighter area has higher backscatter. The backscatter can be influenced by a variety of factors such as surface roughness, moisture of the ground, dielectric constant, penetration depth, physical size of the target object, SAR frequency, polarizations, viewing geometry (incident and azimuth angles), surface slopes, etc. (Jawak et al., 2015).

For interpretations of the signal measured by SAR systems, two scattering mechanisms are considered in the backscatter theory: surface and volume scattering. The surface scattering occurs only at the surface boundary between two different but homogeneous media. For a rougher surface, the backscattering increases while the scattering amplitude along the specular direction decreases (F. Ulaby, Moore, \& Fung, 1982). Volume scattering takes place at the surface boundary between two

\footnotetext{
* Corresponding author
} 
different and inhomogeneous media, a part of the transmitted signal may be scattered back by the inhomogeneity and received by the antenna. Volume scattering coefficient is defined as the total scattering cross-section per unit volume. Figure 1 sketches the surface and volume scattering mechanisms.

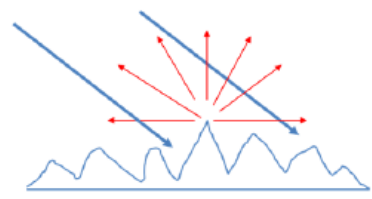

(a) surface scattering

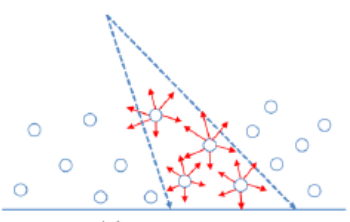

(b) volume scattering
Figure 1. Illumination of scattering: (a) surface scattering (b) volume scattering.

\subsection{Penetration depth}

The penetration depth of SAR signal in snow and ice has been explored since the first spaceborne SAR system launched at the end of last century. Several definitions of penetration depth can be found in the literature and some models of penetration depth were developed based on these definitions and four different penetration depths are widely used in different papers.

2.2.1 Power penetration depth: The power penetration depth is defined by the depth at which the average power of a wave traveling downward within a medium attenuates to $1 / \mathrm{e}$ (about 37\%) of the power at a point just below the surface (Ulaby et al., 1984). For a medium with uniform extinction coefficient $\mathrm{ke}$, the penetration depth is governed by scattering and absorption losses as:

$$
\delta_{p}=\frac{1}{k_{e}}
$$

where $\quad \delta_{\mathrm{p}}=$ power penetration depth

$\mathrm{k}_{\mathrm{e}}=$ extinction coefficient

2.2.2 Scattering Phase center: The signal emitted by an antenna is assumed as a spherical wave and then the phase center is the point from which the wave appears to have come (Müller, 2011). The phase center of a volume distributed target is the location of its apparent focal position. It is the position in space of a single scatterer equivalent to the combined backscatter from all individual scatterer within the radar-beam (Müller, 2011).

The DEM derived by InSAR records the location of the phase center instead of the terrain surface which is always located below the natural surface such as snow, vegetation ground, resulting from the penetration effect of SAR signal. The elevation bias $\delta_{\phi}$ is defined by the difference between the measured elevation derived from an InSAR DEM and the true surface elevation (Dall, 2007).

2.2.3 One-way penetration depth: For the SAR of nadir signal, the one-way vertical penetration depth also depends on the transmission angle $\left(\theta_{t}\right)$ (Abdel Jaber, 2016):

$$
\delta=\frac{\cos \theta_{t}}{k_{e}}
$$

where $\delta=$ one-way penetration depth

$$
\begin{aligned}
& \theta_{\mathrm{t}}=\text { transmission angle } \\
& \mathrm{k}_{\mathrm{e}}=\text { extinction coefficient }
\end{aligned}
$$

2.2.4 Two-way penetration depth: According to the Dall (Dall, 2007), the two-way penetration depth is defined as half of the one-way penetration depth:

$$
\delta^{\prime}=\frac{\cos \theta_{t}}{2 k_{e}}
$$

$$
\text { where } \quad \begin{aligned}
& \delta=\text { two-way penetration depth } \\
& \theta_{\mathrm{t}}=\text { transmission angle } \\
& \mathrm{k}_{\mathrm{e}}=\text { extinction coefficient }
\end{aligned}
$$

In this paper, the X-band SAR Signal penetration depth is the two-way penetration depth $\delta_{\phi}$ which is the elevation difference between the TanDEM-X DEM and the laser altimetry data or GNSS data.

\subsection{Processing chain}

The experiment processing steps are sketched in Figure 2. The TanDEM-X DEM and ILATM2/GNSS are introduced in the next section while the backscattering coefficient image is the intermedia result during the DEM generation. In order to reduce the "salt-and-pepper" noise, a median filter with window size 3 by 3 is applied to the backscattering coefficient image while the window size is selected based on the experiment. Then all the data are processed along each profile to measure the penetration depth. Then Pearson correlation coefficient is applied in order to find the relationship between the penetration depth and backscattering coefficient.

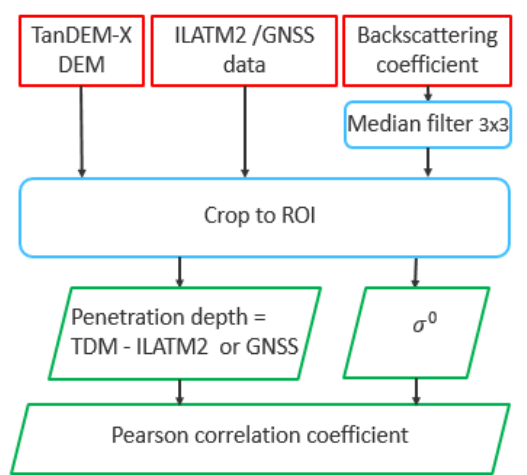

Figure 2. Processing chain

\section{EXPERIMENT AREAS AND DATA}

The detail information of two study sites are provided in this section, then the experiment's data of the investigated areas are described in the following.

\subsection{Study sites}

Two test sites have been taken into consideration in this paper: Recovery Ice Stream, Schirmacher Area. They are selected based on the availability of additional, independent elevation measurements which coincident to the TDM bistatic acquisition. 
Recovery Ice Stream which is located in East Antarctica is flowing west along the southern side of the Shackleton Range in Antarctica. It is the longest dynamic ice-flow features, extending about $1000 \mathrm{~km}$ inland (Fricker et al., 2014). The investigation area which extends from $80^{\circ} 5$ 'S to $82^{\circ} 6$ 'S and $18^{\circ} 4^{\prime} \mathrm{W}$ to $30^{\circ} 59^{\prime} \mathrm{W}$ contains four subglacial lakes (R1, R2, R3 and R4) (Figure 3). These subglacial lakes contribute to the ice flow rate which is varying dramatically, ranging between 2 and 50 meters per year (Kohler, 2007).

The second study site Schirmacher Oasis is located on the edge of the Antarctic Ice Sheet and the Ice Shelf which is a rock barrier to a northward running ice stream and occupies an area of $35 \mathrm{~km}^{2}$. The investigated region (Figure 3) in this paper surrounds the Schirmacher Oasis and extends from $70^{\circ} 15^{\prime} \mathrm{S}$ to $71^{\circ} 30^{\prime} \mathrm{S}$ and $11^{\circ} 4^{\prime} \mathrm{E}$ to $15^{\circ} 59^{\prime} \mathrm{E}$ covering $12900 \mathrm{~km}^{2}$. In this region, blue ice exists. The blue ice areas only exist in Antarctica and cover approximately $1 \%$ of the entire Antarctica surface area (Bintanja, 1999) which are known as the oldest and densest areas in a glacier. Compared with the glacier ice, the blue ice has smaller air bubbles, higher density and a flat, smooth and hard surface which have been used as aircraft landing strips (Mellor and Swithinbank, 1989). The surface of the blue ice areas is generally rippled due to the sublimation by the wind (Bintanja, 1999).

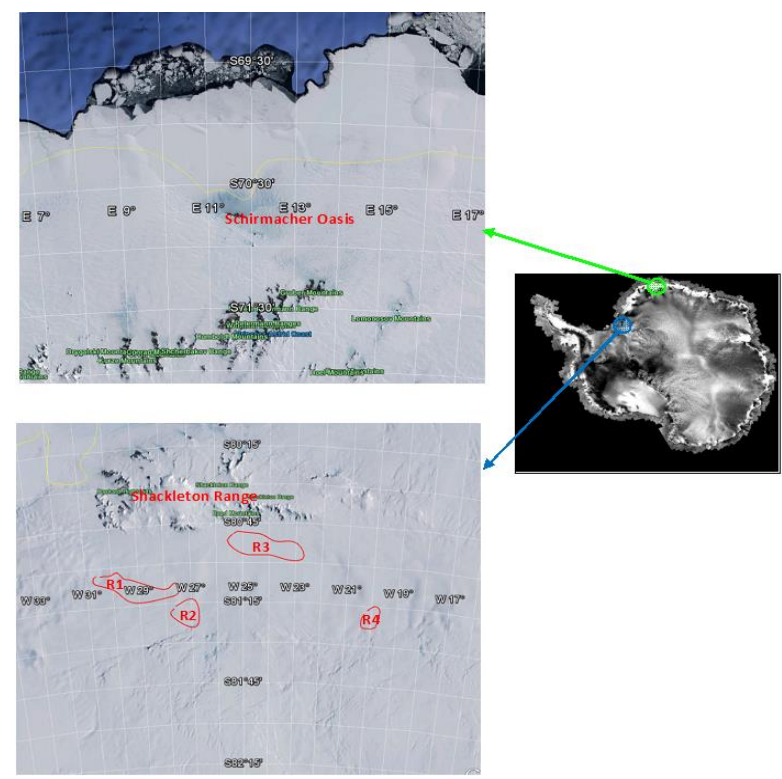

Figure 3. Green circle: Schirmacher Area. Blue circle: Recovery Ice Stream. Red lines: the borders of four subglacial lakes R1R4. Yellow lines: the grounding line.

\subsection{TanDEM-X DEM}

The TanDEM-X DEMs of Recovery Ice Stream and Schirmacher area are used in the experiments which are generated by the Integrated TanDEM-X Processor (ITP) from TanDEM-X bistatic data. The ITP was developed for SAR data quality analysis, interferometric processing and DEM generation by DLR/IMF (Rossi et al., 2012).

In the context of the present study, the TanDEM-X DEM of Recovery Ice Stream (Figure 4) and the TanDEM-X DEM of Schirmacher Area (Figure 5) are used and the detailed information is shown in Table 1.

\begin{tabular}{|l|l|l|}
\hline & \multicolumn{1}{|c|}{$\begin{array}{c}\text { Recovery Ice } \\
\text { Stream }\end{array}$} & \multicolumn{1}{|c|}{$\begin{array}{c}\text { Schirmacher } \\
\text { Area }\end{array}$} \\
\hline Pixel size [arcsec] & $1.0 \times 0.2$ & $1.6 \times 0.8$ \\
Pixel size [m] & $6 \times 6$ & $24 \times 24$ \\
Size [pixels] & $48472 \times 36772$ & $7089 \times 4817$ \\
Size [ km] & $291 \times 221$ & $170 \times 116$ \\
Total area [km $\left.{ }^{2}\right]$ & 64311 & 19720 \\
Coordinates of & $31^{\circ} 13^{\prime} 9.50^{\prime \prime} \mathrm{W}$ & $11^{\circ} 5^{\prime} 59.50^{\prime \prime} \mathrm{E}$ \\
Upper Left Corner & $80^{\circ} 4{ }^{\prime} 23.90 " \mathrm{~S}$ & $70^{\circ} 35^{\prime} 59.50^{\prime \prime} \mathrm{S}$ \\
Coordinates of & $17^{\circ} 45^{\prime} 17.50^{\prime \prime} \mathrm{W}$ & $14^{\circ} 15^{\prime} 1.90^{\prime \prime} \mathrm{E}$ \\
Lower Right Corner & $82^{\circ} 6{ }^{\prime} 58.30 " \mathrm{~S}$ & $71^{\circ} 40^{\prime} 13.10^{\prime \prime} \mathrm{S}$ \\
TanDEM-X data & 2015 & 2013 \\
acquisition time & \multicolumn{2}{|l}{} \\
\hline
\end{tabular}

Table 1. Detailed information of the two study sites DEMs.

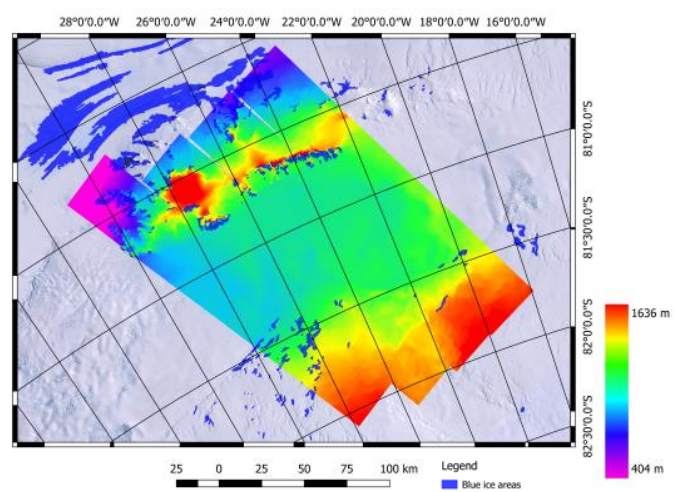

Figure 4. The DEM of Recovery Ice Stream acquired in 2015. The background image is the Landsat RGB Antarctica image acquired in 2011; cyan: the blue ice areas.

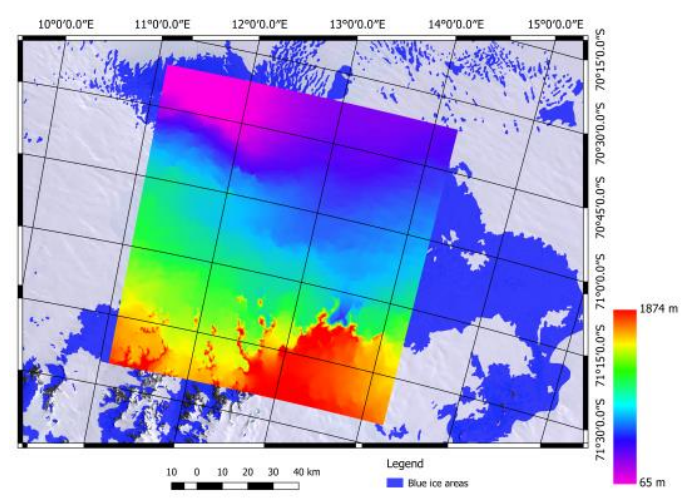

Figure 5. The DEM of Schirmacher Area superimposed on the blue ice area map.

\subsection{The ATM data over Recovery Ice Stream}

The laser altimetry data over Recovery Ice Stream used in this investigation was acquired by the IceBridge ATM L2 (ILATM) on October $25^{\text {th }}, 2014$. The spatial resolution of ATM data is 80 $\mathrm{m}$ sample width and $40 \mathrm{~m}$ spacing along the track (Krabill, 2010, updated 2016). 


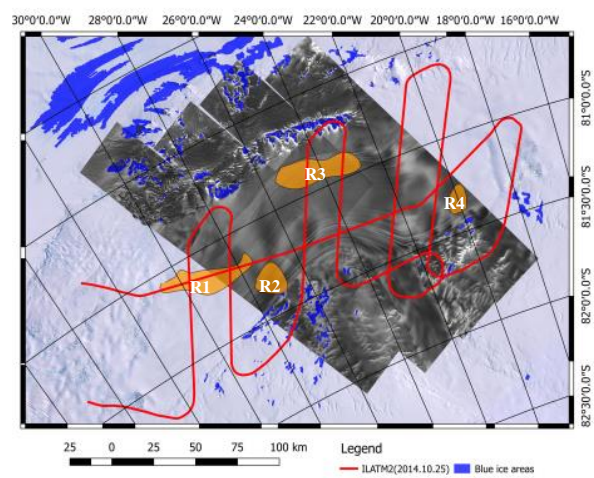

Figure 6. The flight trajectory of ATM on 2014.10.25 in yellow. The subglacial lakes are outlined by orange/black lines. The background is the MODIS Image Mosaic of Antarctica (MOA). Colors in basemap indicate ice surface velocity with warmer colors for faster velocities.

\subsection{The GPS data over Schirmacher Oasis Region}

The GPS data which are used to investigate the Schirmacher area in this paper are provided by the Institute für Planetare Geodäsie, Technische Universität Dresden. The kinematic GNSS tracks were measured on 16.01. 2011 and 02.01.2015 over the blue ice area (Figure 7) which covers an area of about $2000 \mathrm{~km}^{2}$ (Scheninert, Knöfel, \& Schröder, 2016) and the error of the GPS data is in centimeter level. Based on the research of the Technische Universität Dresden, the ice surface height of this blue ice area has changed over time and the height change keeps positive from 2010 to 2015 (Scheninert et al., 2016).

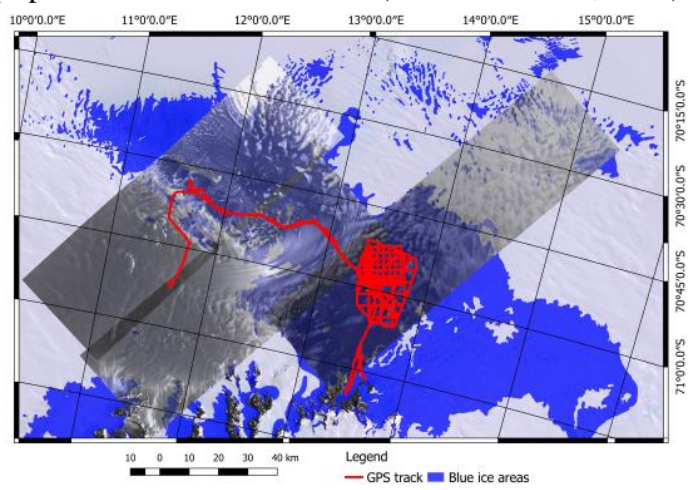

Figure 7. The kinematic GPS tracks in Schirmacher Oasis Area in red superimposed on the blue ice area in cyan.

\section{RESULTS AND DISCUSSION}

In the experiment, eight profiles have been selected to measure the X-band SAR signal penetration depth and to study the relationship between penetration depth and backscattering coefficient.

On Recovery Ice Stream, four profiles (profile I, II, III and IV) on the snow-covered areas have been selected and discussed in detail (Figure 8). Then on Schirmacher area, the intensive GPS measurements (Figure 9) with several tracks were carried out by TU Dresden. Most of the GPS measurements are located on the blue ice areas, especially on scene 3 and only a few GPS data are located on the snow-covered area. profile $\mathrm{V}$ is the longest GPS track laying on the snow-covered area and profile VI is the longest GPS track on the blue ice area crossing all three scenes, while profile VII and profile VIII are the grid tracks laying only on the blue ice region.

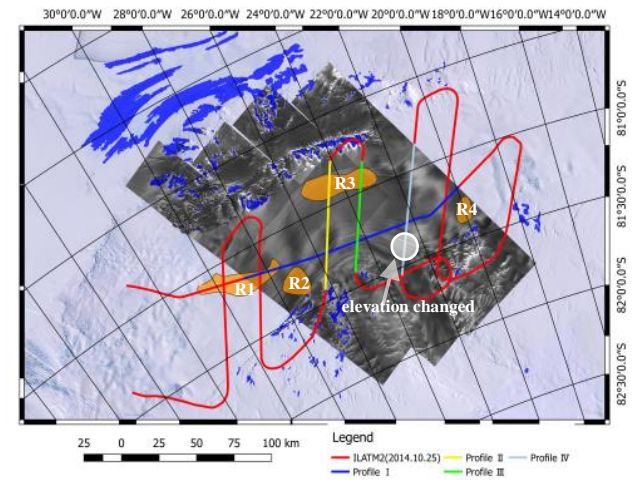

Figure 8 . The flight paths of the ILATM data and the four profiles selected on the main trunk of Recovery Ice Stream.

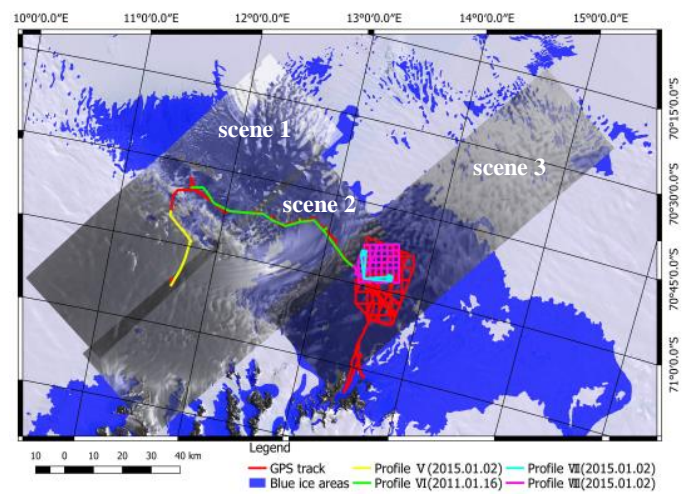

Figure 9. The tracks of the GNSS data and the four profiles selected on Schirmacher area.

\subsection{Recovery Ice Stream}

Based on the previous study, the elevation of most areas on Recovery Ice Stream did not have an obvious change from 2013 to 2015. However, an obvious elevation change has been found in the specific area where obvious glacier flow can be observed from the SAR intensity image (Figure 8). The surface elevation along profile IV with the longitude extends from $-22.6^{\circ}$ to $22.1^{\circ}$ has an obvious surface elevation changes up to $11 \mathrm{~m}$ and this part is not considered in the experiment.

Figure 10 shows that on Recovery Ice Stream the elevation bias $\Delta H$ ranges from $-3.5 \mathrm{~m}$ to $-5.7 \mathrm{~m}$ and the backscattering coefficient $\sigma^{0}$ ranges between $-5.8 \mathrm{~dB}$ and $-8.1 \mathrm{~dB}$. Due to the SAR signal penetration effect in dry snow, the scattering phase center might be located several meters below the actual surface while DEM generated by InSAR records the location of the scattering phase center. Thus, the surface elevation obtained from TanDEM-X might be lower than the LiDAR ATM altimetry measurement and the elevation difference $h_{T D M}-h_{A T M}<0$. Due to the geographic location of the Recovery Ice Stream, only dry snow exists. It can be concluded that the $\mathrm{X}$-band SAR signal penetration depth in dry snow is around 3.5 $\mathrm{m}$ to $5.7 \mathrm{~m}$.

According to the scatter plots of profile I, II, III and IV, a linear relationship between $\Delta H$ and $\sigma^{0}$ can be assumed. The linear fit of each profile and the Pearson correlation coefficient of $\Delta H$ and $\sigma^{0}$ are presented in Figure 11. Generally, the strength of the correlation can be described by the absolute value of $r$ as following (Evans, 1996): 


$\begin{array}{ll}\text { - } & 0-0.19 \text { very weak } \\ \text { - } & 0.2-0.39 \text { weak } \\ \text { - } & 0.4-0.59 \text { moderate } \\ & 0.6-0-79 \text { strong } \\ & 0.8-1 \text { very strong }\end{array}$

\section{Profile I}

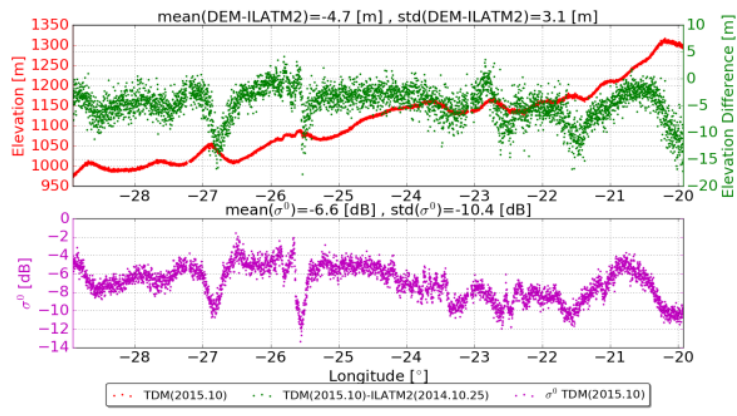

Profile III

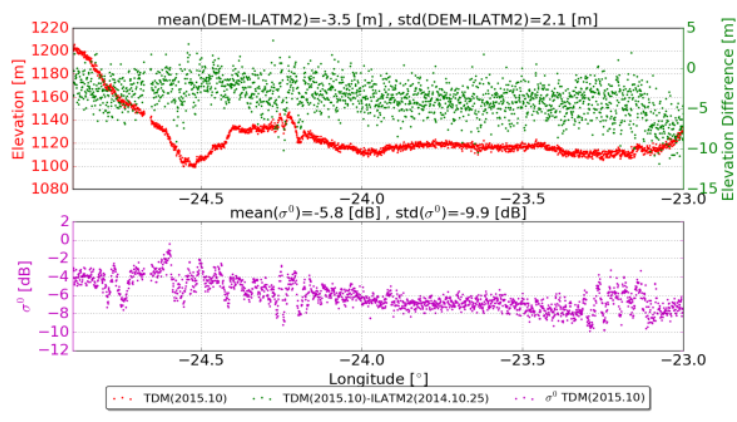

Profile V

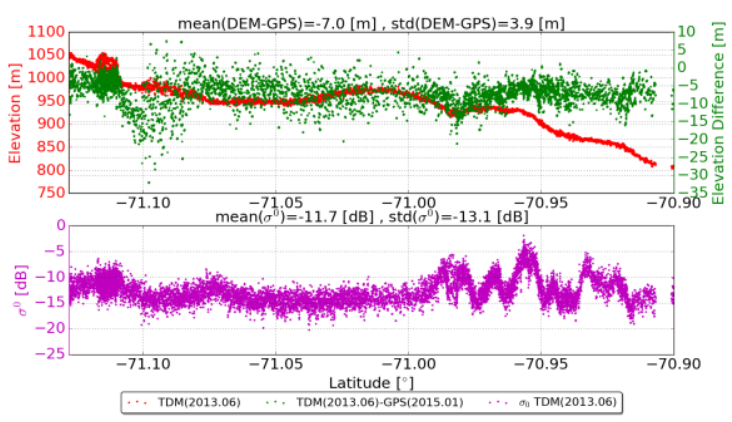

profile VII

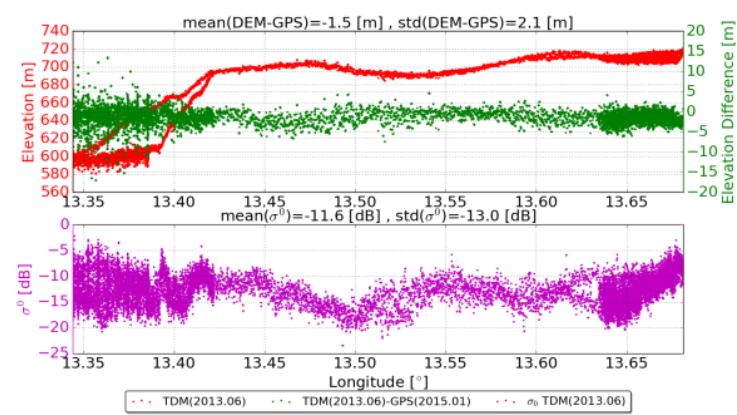

It is obviously that the Pearson correlation coefficient of this four profiles ranges from 0.23 to 0.54 which shows a moderate or weak dependence between the penetration depth and backscattering coefficient.

\section{Profile II}

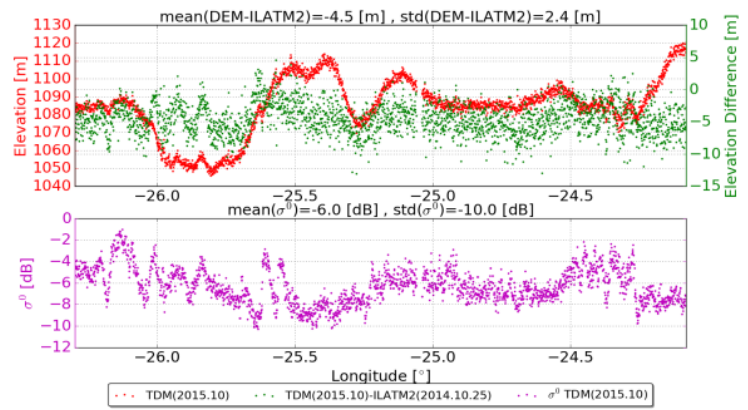

Profile IV

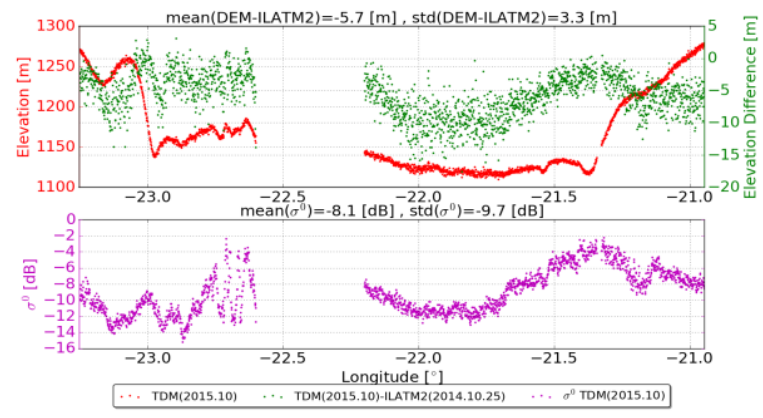

profile VI
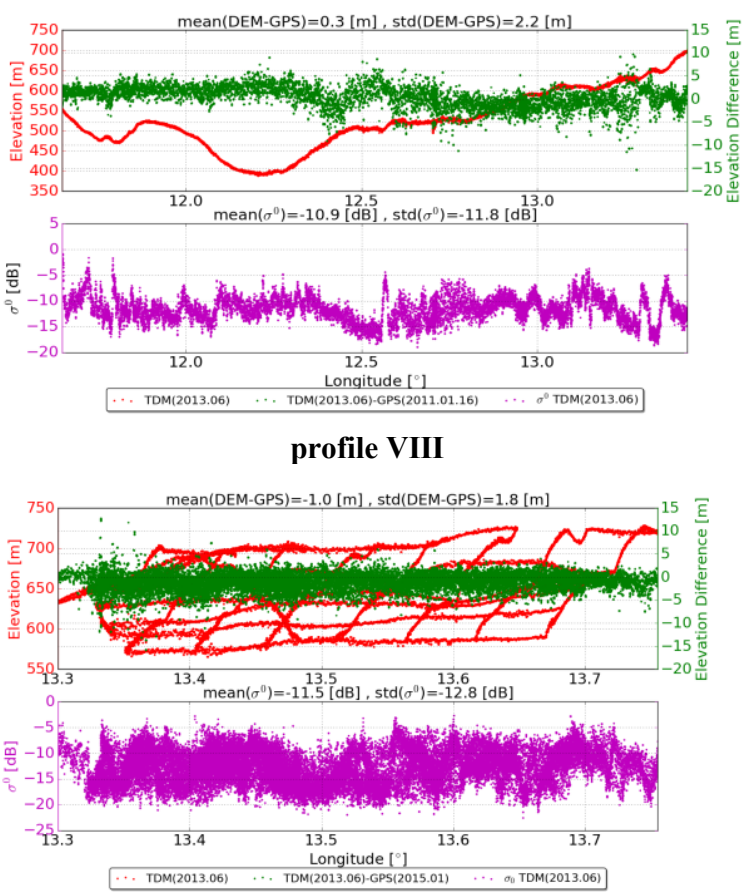

Figure 10. Comparison of TDM elevation (red), elevation difference between TDM and ATM (green) and the X-band backscattering coefficient (purple) along profile I, profile II, profile III, profile IV on Recovery Ice Stream. Comparison of TDM elevation (red), elevation difference between TDM and GPS (green) and the X-band backscattering coefficient (purple) along profile $\mathrm{V}$, profile VI, profile VII, profile VIII on Schirmacher Area. 
Profile I

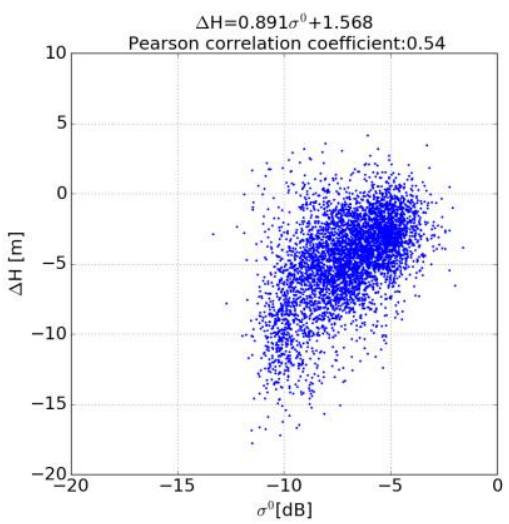

Profile IV

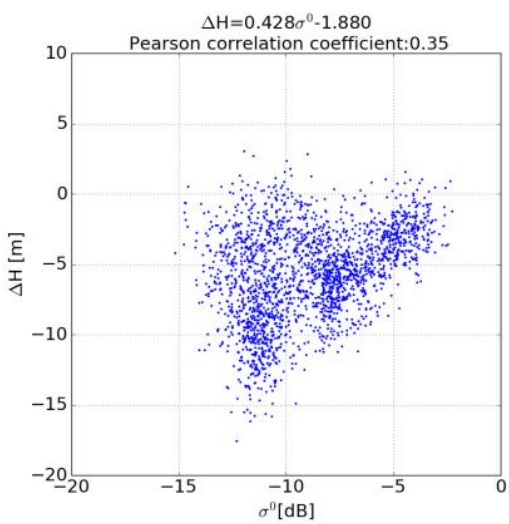

profile VII

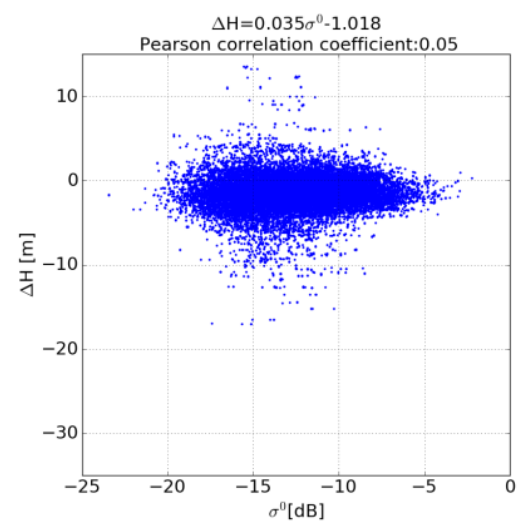

Profile II

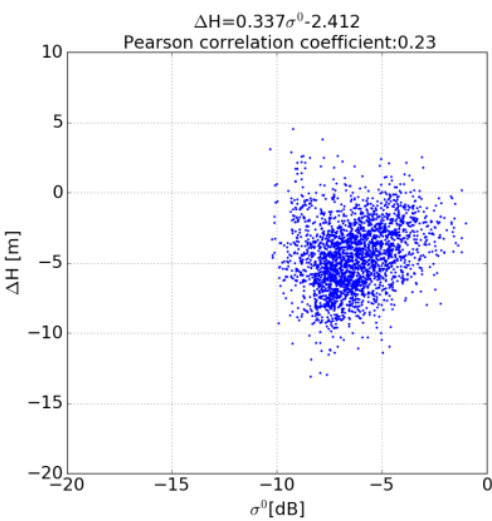

Profile V

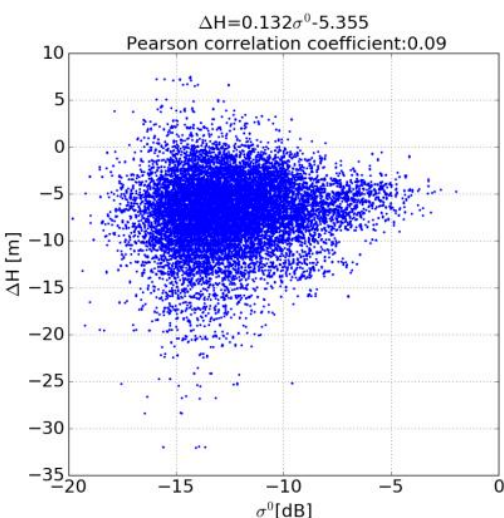

\section{Profile III}

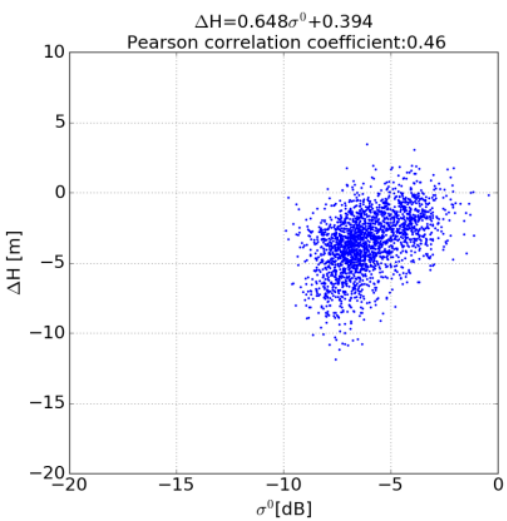

profile VI

$\Delta \mathrm{H}=-0.063 \sigma^{0}-0.397$

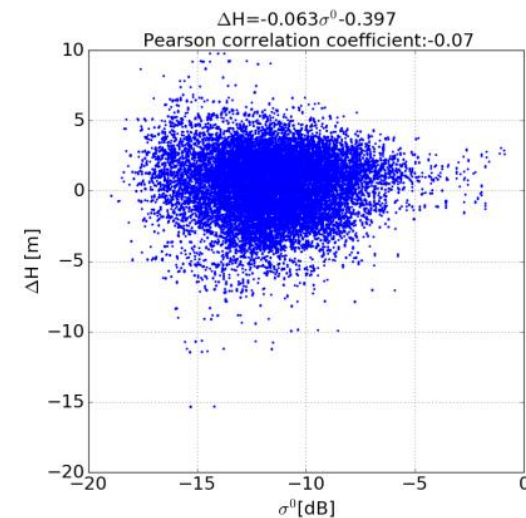

profile VIII

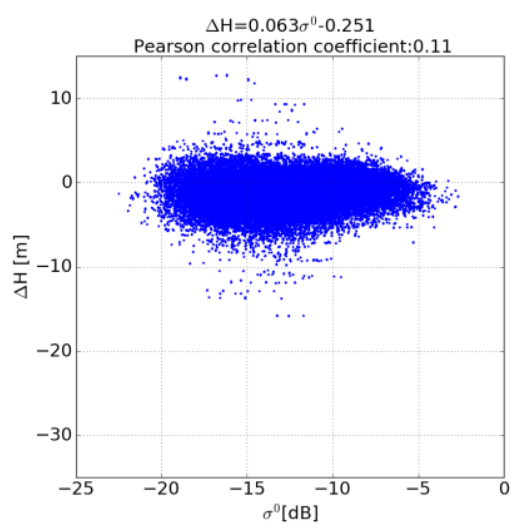

Figure 11. The scatter plot between the TDM-GPS elevation difference and $\sigma^{0}$ along profile I, profile II, profile III, profile IV, profile $\mathrm{V}$, profile VI, profile VII, profile VIII

\subsection{Schirmacher Area}

Profile V (Figure 10) crosses a snow area only where the blue ice is absent. The mean $\Delta H$ is $-7.0 \mathrm{~m}$ and the standard deviation is $3.9 \mathrm{~m}$. The mean $\sigma^{0}$ is $-11.7 \mathrm{~dB}$ and the corresponding standard deviation is $-13.1 \mathrm{~dB}$.

The GPS track of profile VI (Figure 10) traverses the blue ice area around Schirmacher and stretches along all the three TanDEM-X scenes, the mean elevation difference between TDM and GPS is $0.3 \mathrm{~m}$ and the corresponding standard deviation is $2.2 \mathrm{~m}$. The mean backscattering coefficient is -10.9 $\mathrm{dB}$ with a corresponding standard deviation of $-11.8 \mathrm{~dB}$.

Along profile VII and profile VIII, the mean $\Delta H$ is $-1.5 \mathrm{~m}$ and $-1.0 \mathrm{~m}$ respectively and the corresponding standard deviation is $2.1 \mathrm{~m}$ and $1.7 \mathrm{~m}$. The mean $\sigma^{0}$ is $-11.7 \mathrm{~dB}$ along profile VII and $-11.5 \mathrm{~dB}$ along profile VIII while the corresponding standard deviation is $-13.0 \mathrm{~dB}$ along profile VII and $-12.8 \mathrm{~dB}$ along profile VIII.

No linear relationship between $\sigma^{0}$ and $\Delta H$ can be found along profile V, profile VI, profile VII and profile VIII. Figure 11 
shows clearly that the $\sigma^{0}$ of most GPS points in blue ice region ranges from $-20 \mathrm{~dB}$ to $-10 \mathrm{~dB}$ while most laser points in dry snow have a backscattering coefficient ranges from $-10 \mathrm{~dB}$ to -5 $\mathrm{dB}$. It indicates that the $\sigma^{0}$ in blue ice is lower than the $\sigma^{0}$ in the dry snow area.

\subsection{Discussion}

Table 2 summarizes the experiment results of eight profiles in the previous sections. Four profiles have been selected in each study site respectively and before the discussion of the results, the natural environment of these two sites have been studied. These two study sites have a totally different nature environment. The Recovery Ice Stream are in the dry snow zone where the typical temperature in summer is $-25^{\circ} \mathrm{C}$ and no melting occurs which means that this site only has dry snow at the surface with low snow accumulation. Meanwhile, the Schirmacher area has both dry snow zone and blue ice regions and the winter average temperature is $-22^{\circ} \mathrm{C}$ which indicates that it has the dry snow surface with low accumulation and blue-ice region. The natural difference between these two sites may contribute to the snow conditions which result in the difference backscattering coefficient pattern.

\begin{tabular}{|c|c|c|c|c|c|c|}
\hline \multirow{2}{*}{ Profile } & \multirow{2}{*}{ Location } & \multirow{2}{*}{$\begin{array}{c}\text { Surface } \\
\text { condition }\end{array}$} & \multicolumn{2}{|c|}{$\Delta H[\mathrm{~m}]$} & \multicolumn{2}{|c|}{$\sigma^{0}[\mathrm{~dB}]$} \\
\hline & & & mean & std & mean & std \\
\hline I & \multirow{4}{*}{$\begin{array}{l}\text { Recovery } \\
\text { Ice Stream }\end{array}$} & \multirow{5}{*}{$\begin{array}{c}\text { Dry } \\
\text { snow } \\
\text { (low } \\
\text { acc.) }\end{array}$} & -4.7 & 3.1 & -6.6 & -10.4 \\
\hline II & & & -4.5 & 2.4 & -6.0 & -10.0 \\
\hline III & & & -3.5 & 2.1 & -5.8 & -9.9 \\
\hline IV & & & -5.7 & 3.3 & -8.1 & -9.7 \\
\hline $\mathrm{V}$ & \multirow{4}{*}{$\begin{array}{c}\text { Schirmacher } \\
\text { Area }\end{array}$} & & -7.0 & 3.9 & -11.7 & -13.1 \\
\hline VI & & \multirow{3}{*}{ Blue ice } & 0.3 & 2.2 & -10.9 & -11.8 \\
\hline VII & & & -1.5 & 2.1 & -11.6 & -13.0 \\
\hline VIII & & & -1.0 & 1.8 & -11.5 & -12.8 \\
\hline
\end{tabular}

Table 2. The summary of the experiment results

In the dry snow-covered areas (profiles I, II, III, IV and V), the SAR signal two-way penetration depth is about 3.5 to 6.1 meters and the backscattering coefficient ranges from $-11.1 \mathrm{~dB}$ to $-5.8 \mathrm{~dB}$. The penetration depth and backscattering coefficient along profile $\mathrm{V}$ do not have similar value as the results measured along other four profiles which can be attributed to the difference in the natural environment.

In the blue-ice areas (profile VI, profile VII and profile VIII), $\Delta H$ ranges from $-1.5 \mathrm{~m}$ to $0.3 \mathrm{~m}$ which is smaller than the accuracy of TanDEM-X DEM $( \pm 2 \mathrm{~m})$, therefore no penetration depth is expected. The SAR signal two-way penetration depth along profile VI is $0.3 \mathrm{~m}$ which indicates a thickening of the blue-ice areas on Schirmacher area confirmed by the repeat GPS measurements carried out by TU Dresden. The backscattering coefficient in blue ice region is around $-11 \mathrm{~dB}$ which is lower than for the profiles located in the snow-covered areas.

A linear relationship between the backscattering coefficient and the elevation difference can be established in dry snow area but not in the blue ice area. However, this is an empirical relationship which doesn't by far match the complexity of the backscattering modeling based on the electromagnetic theory, which would be far beyond the aim of this paper.

\section{CONCLUTION AND OUTLOOK}

This paper demonstrates that the SAR signal penetration depth effect on the TanDEM-X absolute elevations over dry snow is about $3 \mathrm{~m}$ to $6 \mathrm{~m}$ and no penetration depth is expected in blueice region in Antarctica. The SAR signal two-way penetration depth is estimated as the elevation difference between TanDEM-X DEM and the ATM laser altimetry elevations or the GPS measurements. Although the X-band SAR signal penetration depth in dry snow and blue ice has been measured successfully, there are few considerations that worth to mention.

Firstly, the study results are limited by the TanDEM-X DEM absolute vertical accuracy. During the generation of the DEM of Recovery Ice Stream used in this paper, the TanDEM-X DEM generated from data acquired in 2013 and corrected with IceBridge ATM laser altimetry elevations is used as the reference with no static GPS point is available in this area. Then the absolute vertical accuracy of DEM used in this paper may be influenced by the DEM generation approach. The study result may be more reliable if the DEM is calibrated with several static GPS points which are evenly distributed in the study area.

Secondly, the spatial coverage of the profiles can also influence the study results. Based on the four profiles in Recovery Ice Stream, a linear dependence could be found. However, more measurements and longer profiles are needed to validate this assumption.

Lastly, the relationship between the SAR penetration depth and the backscattering coefficient in dry snow could be further studied and the accurately model could be developed in the future. Meanwhile, no backscattering modeling of blue-ice exists which could also be a part of the future work.

\section{ACKNOWLEDGEMENTS}

This work is supported by the project "Remote Sensing and Earth System Dynamics" of the Helmoltz Alliance (HGF). TanDEM-X data were provided through the science proposal XTI_GLAC7035 and the Kinematic GPS data on Schirmacher area were provided by Dr. Mirko Scheinert from TU Dresden.

\section{REFERENCES}

Abdel Jaber, W., 2016. Derivation of mass balance and surface velocity of glaciers by means of high resolution synthetic aperture radar: application to the Patagonian Icefields and Antarctica (Doctoral dissertation, Technische Universität München).

Bamber, J.L., Gomez-Dans, J.L. and Griggs, J.A., 2009. A new $1 \mathrm{~km}$ digital elevation model of the Antarctic derived from combined satellite radar and laser data-Part 1: Data and methods. The Cryosphere, 3(1), p.101.

Bintanja, R., 1999. On the glaciological, meteorological, and climatological significance of Antarctic blue ice areas. Reviews of Geophysics, 37(3), pp.337-359.

Chen, J.F., Zagzebski, J.A. and Madsen, E.L., 1993. Tests of backscatter coefficient measurement using broadband pulses. IEEE transactions on ultrasonics, ferroelectrics, and frequency control, 40(5), pp.603-607. 
Dall, J., 2007. InSAR elevation bias caused by penetration into uniform volumes. IEEE Transactions on Geoscience and remote sensing, 45(7), pp.2319-2324.

Evans, J.D., 1996. Straightforward statistics for the behavioral sciences. Brooks/Cole.

Fricker, H.A., Carter, S.P., Bell, R.E. and Scambos, T., 2014. Active lakes of Recovery Ice Stream, East Antarctica: a bedrock-controlled subglacial hydrological system. Journal of Glaciology, 60(223), pp.1015-1030.

Jawak, S.D., Bidawe, T.G. and Luis, A.J., 2015. A review on applications of imaging synthetic aperture radar with a special focus on cryospheric studies. Advances in Remote Sensing, 4(02), p.163.

Kohler, J., 2007. Glaciology: lubricating lakes. Nature, 445(7130), pp.830-831.

Krabill, W.B., 2010, updated 2016. IceBridge ATM L2 Icessn Elevation, Slope, and Roughness. Version 2. [October 25th 2014], in: Boulder, C.U.N.D.a.t.N.S.a.I.D.C. (Ed.). Boulder, Colorado USA: NASA DAAC at the National Snow and Ice Data Center. http://dx.doi.org/10.5067/CPRXXK3F39RV.

Liu, H., Jezek, K.C. and Li, B., 1999. Development of an Antarctic digital elevation model by integrating cartographic and remotely sensed data: A geographic information system based approach. Journal of Geophysical Research: Solid Earth, 104(B10), pp.23199-23213.

Mellor, M. and Swithinbank, C., 1989. Airfields on Antarctic glacier ice (No. CRREL-89-21). COLD REGIONS RESEARCH AND ENGINEERING LAB HANOVER NH.

Müller, K., 2011. Microwave penetration in polar snow and ice: Implications for GPR and SAR (Doctoral dissertation, University of Oslo).

Rossi, C., Gonzalez, F.R., Fritz, T., Yague-Martinez, N. and Eineder, M., 2012. TanDEM-X calibrated raw DEM generation. ISPRS Journal of Photogrammetry and Remote Sensing, 73, pp.12-20.

Ulaby, F.T., Stiles, W.H. and AbdelRazik, M., 1984. Snowcover influence on backscattering from terrain. IEEE Transactions on geoscience and remote sensing, (2), pp.126133.

Vaughan, D.G., Comiso, J.C., Allison, I., Carrasco, J., Kaser, G., Kwok, R., Mote, P., Murray, T., Paul, F., Ren, J. and Rignot, E., 2013. Observations: cryosphere. Climate change, 2103, pp.317-382. 